\title{
La práctica de la catalogación temática en perspectiva sociocognitiva
}

\author{
A prática da catalogação de assunto em perspectiva sociocognitiva
}

The subject cataloguing practice from a socio-cognitive approach

Mariângela Spotti Lopes FuJITA (1), Paula Regina DAL' EVEdove (2)

(1) Universidade Estadual Paulista "Júlio de Mesquita Filho" - UNESP, Faculdade de Filosofia e Ciências, Av. Hygino Muzzi Filho, 737, Campus Universitário, CEP. 17525-900 - Marília/SP, Brasil, Caixa-Postal: 421. (2) fujita@marilia.unesp.br; (2) sud_dove@yahoo.com.br

\begin{abstract}
Resumen
La catalogación temática consiste en una operación mental asociada directamente al desempeño profesional. Por ello, las acciones cotidianas del catalogador temático y sus articulaciones en los diferentes ambientes informacionales deben ser observadas, a fin de comprender el contexto real de los productos informacionales que resultan de la catalogación de materias. Se considera, en definitiva, que la actuación profesional y el contexto de trabajo son indisociables. Desde esta perspectiva, resulta necesario que las investigaciones sobre la catalogación temática incluyan preguntas relativas a la naturaleza de las estructuras de conocimiento compartidas. En ese contexto, este estudio presenta una reflexión en torno de la perspectiva sociocognitiva que permea las acciones desempeñadas por los profesionales en la catalogación temática.
\end{abstract}

Palabras clave: Catalogación temática. Práctica profesional. Abordaje sociocognitivo.

\section{Introdução}

A missão social (1) do profissional da informação é atuar como elo entre as informações constantemente difundidas nos mais diversos suportes e o usuário, ser ativo na busca por novos conhecimentos. Portanto, facilitar o acesso informacional pela e para a sociedade, com fins de promoção e socialização do conhecimento. Tal elo entre a informação e o usuário exige do profissional da informação além de técnicas e habilidades específicas, um compromisso ético com a sociedade.

Para tal feito, a necessidade de informação deve ser respaldada pelo pragmatismo como concepção epistemológica, uma vez que a manifestação das necessidades de informação dáse mediante os processos cognitivos dos sujeitos associados a contextos históricos, sociais e culturais. Neste sentido, à função social da Ciência da Informação volta-se para a compreen-

\begin{abstract}
Subject cataloguing consists of a mental operation directly associated with the professional performance. Thus, the subject cataloguer's daily actions must be observed in order to understand the real context of the informational products that result of the process of subject cataloguing, taking into account that the professional performance and the work context are inseparable. In this perspective, it is necessary that research on subject cataloguing includes questions concerning the nature of the cataloguers' shared knowledge structure. In this context, this study presents a reflection from the socio-cognitive approach on the activities developed by subject cataloguing professionals.
\end{abstract}

Keywords: Subject cataloguing. Professional performance. Socio-cognitive approach.

são dos sujeitos em suas relações individuais e coletivas na busca pela informação. Dito de outro modo, a Ciência da Informação põe "a ênfase no ser humano e na sociedade como um todo, e todas as suas formas de pensar, conhecer, agir e comunicar" (Shera, 1973, p. 90).

$\mathrm{Na}$ perspectiva profissional, essa vertente decorre da mente humana suportar as capacidades cognitivas necessárias a sua sobrevivência e ao seu bem-estar, bem como por conferir-lhe a capacidade de exibir uma identidade e de agir como um todo coerente em contextos específicos, uma vez que os processos sociais e culturais participam ativamente do desenvolvimento de habilidades cognitivas individuais.

Considerando que a catalogação de assunto consiste numa operação mental associada diretamente ao desempenho profissional, a construção dos métodos e instrumentos não deve basear-se apenas nos processos cognitivos residentes na mente humana, mas, sobretudo, em 
regras socialmente construídas (Frohmann, 1990). Em vista disto, torna-se eminente que as investigações de ordem cognitiva cerquem questões relativas à natureza das estruturas de conhecimento compartilhadas e todas as atividades subsequentes de organização e representação da informação. Em outras palavras, observar as ações profissionais ancoradas na realidade do contexto de trabalho de modo a compreender os processos sociocognitivos envolvidos na catalogação de assunto, mediante a esfera dos aspectos técnicos e comportamentais.

Nesse contexto, são tecidas reflexões sobre a perspectiva sociocognitiva que permeia as ações desempenhadas pelos profissionais na catalogação de assunto. Para tanto, analisa-se a questão da subjetividade que permeia a prática profissional a partir da percepção dos catalogadores de assunto obtida por meio da técnica introspectiva de coleta de dados - Protocolo Verbal.

Mediante os resultados advindos pela percepção do grupo de catalogadores de assunto investigado, evidencia-se a importância das ações dos profissionais serem baseadas e condicionadas pela perspectiva sociocognitiva, no intuito de contribuir com investigações destinadas ao desenvolvimento de instrumentos metodológicos que propiciem sustentabilidade prática a catalogação de assunto.

\section{O catalogador de assunto sob o prisma do contexto sociocognitivo}

Uma das lacunas na atuação dos catalogadores de assunto decorre da falta de parâmetros metodológicos que sustentem a prática profissional na busca por resultados mais satisfatórios no momento da catalogação de assunto e, paralelamente, que contribuam para a diminuição das variações nos resultados, uma vez que cada profissional possui percepções ${ }^{2}$ diferentes sobre o mesmo documento. Notadamente, este fator acarreta níveis de avaliações diferenciados dependendo do profissional sobre a mesma realidade, cujas variações comprometem a qualidade dos produtos gerados e, também, a resposta as expectativas dos usuários.

A falta de procedimentos que contemplem o fazer profissional resulta em dispares nos produtos finais e prejudica a recuperação da informação. Hutchins (1977, p. 01) lembra que não é necessário entender como os catalogadores de assunto "[...] chegaram a uma descrição particular do conteúdo de um documento, tudo que importa é se permite aos usuários encontrar o documento quando requerido", posto que a realidade exija que o propósito final seja conhecido, sem mesmo haver uma clareza quanto ao processo. O referido autor alerta que até poderia haver uma satisfação sob este viés, porém, esta seria superficial devido à consciência profissional sobre a carência de parâmetros metodológicos que norteiem a prática profissional. Ademais, a atuação do catalogador de assunto não pode ser superficial, com fins apenas de recuperação da informação como meta maior, mas deve debruçar-se sobre a confiabilidade dos resultados, valendo-se da tríplice profissional-usuário-contexto, bem como de todas as formas de relações e completudes.

Um dos objetivos da Ciência da Informação é fomentar discussões que permitam o seu aprimoramento teórico-metodológico e promovam conexões entre contextos informacionais e sujeitos na busca pela informação. Enquanto campo científico, sua atenção volta-se para os estudos de fenômenos subjacentes a produção, organização, representação, circulação e uso da informação nos diferentes contextos e domínios, cuja finalidade respalda-se na "[...] criação de instrumentos e no estabelecimento de metodologias que viabilizem a transferência de informações" (Novellino, 1996, p. 37).

A preocupação em torno de métodos e instrumentos eficazes que garantam a qualidade do produto informacional respalda-se, sobretudo, no meio acadêmico e profissional. Um voltado para estudos relativos à representação da informação documental, o outro, responsável por aplicar na prática cotidiana tais conceitos e procedimentos metodológicos. Isto porque, as técnicas e os procedimentos utilizados pelos catalogadores de assunto são ou deveriam ser baseados, sobretudo, nos resultados teóricos "[...] da Ciência da Informação e em contra partida, os teóricos deveriam estudar as técnicas e os procedimentos aplicados na profissão" (Borko, p. 02, 1968).

Presume-se, portanto, que a teoria e a prática devam estar interconectadas, com fins de troca e garantia de repercutir com satisfação as exigências atuais. Tal elucidação respalda-se na crença de que a teoria e a prática profissional estão inexoravelmente relacionadas, em que um alimenta o trabalho do outro (Borko, 1968). Para tanto, o catalogador de assunto deve compreender a importância de suas ações cotidianas desempenhadas em contextos específicos e repercutidas no usuário final.

No que tange a pesquisa em catalogação de assunto sob a perspectiva profissional, deve-se considerar o comportamento profissional e as características inerentes durante a realização do processo, sendo este altamente subjetivo, pois os conceitos abstraídos são fenômenos de natu- 
reza subjetiva, sendo informativos de acordo com o contexto de enunciação. Ademais (Hjørland, 2002, p. 431),

[...] não podemos esperar aprender sobre nossa própria profissão estudando o comportamento de não-profissionais, entretanto, podemos [e devemos] obter suas análises sobre preferências, percepções, dificuldades e procedimentos acerca do uso de serviços de informação para compará-los com resultados de outras pesquisas que visam à compreensão do contexto.

Uma das preocupações em catalogação de assunto respalda-se na utilização do bom sendo profissional. Tal atitude acaba incidindo preconceitos, valores e opiniões pessoais dos profissionais sobre determinado assunto. Inevitavelmente, sendo um ser ideológico e culturalmente social (3), o aspecto da neutralidade dificilmente será zelado, pois "sendo a linguagem intrinsecamente comprometida com o cultural e ideológico, tanto o processo de produção do texto, quanto o de recepção não se isentam destes componentes" (Cintra, 1989, p. 31).

Em estudo investigativo sobre catalogadores de assunto, Sauperl (2002, p. 02) apontou que "as regras não escritas e as práticas usadas durante o processo de análise de assunto" estavam mais evidentes do que os padrões e ferramentas próprias de representação temática da informação documental. Isto demonstra, além da complexidade do processo, a ativa necessidade de parâmetros metodológicos específicos que garantam, pelo menos em parte, uma prescrição qualitativa aos produtos informacionais.

Diante desta realidade, defende-se que os principais pontos a serem observados para a sistematização da catalogação de assunto pela vertente profissional sejam fatores inerentes à natureza da informação, as diversas circunstâncias do contexto e a singularidade do usuário. Por conseguinte, a observação investigativa em torno da catalogação de assunto volta-se para a verificação da prática profissional em contexto específico de informação sob o viés da abordagem sociocognitiva.

\section{A abordagem sociocognitiva na catalogação de assunto}

A formação do conhecimento ocorre mediante um "[...] movimento contínuo de equilibração entre a aprendizagem duradoura e as aquisições decorrentes da experiência" (Varela r Barbosa, 2007, p. 119). Sob este viés, o contexto torna-se uma variável importante na catalogação de assunto, uma vez que reflete as experiências profissionais e as necessidades próprias dos usuários.
Para que o significado do conteúdo dos documentos seja o menos ambíguo possível, Pinto Molina (1993) salienta que os documentos devem ser analisados de acordo com o contexto no qual estão inseridos, uma vez que tal variável tende a agregar valor em determinados conceitos, os quais passam a assumir novos significados apenas mudando-se o contexto de análise. Então, o conceito assume sentido quando levado em consideração o contexto de situação, em que o leitor profissional deve ajustá-lo as suas decisões conforme a necessidade exigida pelo meio.

No âmbito da Organização e Representação do Conhecimento, a análise e a identificação de conceitos por meio da leitura documental possuem aspecto sociocognitivo. Logo, não é um processo sistemático de etapas consecutivas, mas uma estratégia de leitura em análise de assunto, ou seja, um processamento mental de informações que depende do conhecimento prévio, sendo composto de habilidades operatórias de pensamento.

Para Ward (1996) o conhecimento prévio atua como um fator condicionante da prática profissional no que tange a análise de assunto. A este respeito, Naves (2002) aponta que, para a realização de uma análise de assunto consistente, torna-se necessário que o profissional tenha familiaridade prévia com os objetivos e a política do contexto de informação, conhecimento dos princípios e da terminologia específica da área em que atua e do seu respectivo tema de análise.

A abordagem cognitiva de leitura procura desvendar os processos cognitivos subjacentes a esta habilidade. Sobre isto, Salles e Parente (2002, p. 323) expõem que os processos bási$\cos$ da leitura como à identificação de letras, reconhecimento de palavras, acesso ao significado, integração sintática e semântica são requisitos necessários, mas não suficientes, considerando-se que "uma compreensão textual bem sucedida exige processos cognitivos de alto nível, como capacidade de realizar inferências, habilidades linguísticas gerais, habilidades de memória, conhecimento de mundo [...]", que juntos contribuem e condicionam para a construção de uma representação macroestrutural do texto.

Observa-se que, por ser um processamento intelectual de informações, a catalogação de assunto depende, necessariamente, dos processos cognitivos. Sendo assim, torna-se necessário o domínio do contexto físico, abordando todas as condições de infra-estrutura física e material do contexto informacional; do contexto psicológico referente às condições do leitor, seus interesses, motivação e objetivo de leitura 
e; do contexto sociocognitivo que envolve o conhecimento prévio ou cognição do leitor profissional (Fujita, 2007).

Os processos cognitivos adquirem uma ressonância predominante nos processos de organização e representação da informação. No entendimento de Goldmann (1973), o ato ou ação de entender uma determinada informação significa que, primeiramente, o sujeito a considerou como uma totalidade relativa (estrutura) para, em seguida, submetê-la a uma operação mental que verificou a função e suas partes constitutivas (dependências internas). Logo, o catalogador de assunto deve compreender o contexto de atuação no qual está inserido, com intuito de refletir sociocognitivamente o processo de tratar e representar as informações documentais. Esta prerrogativa assenta-se no fato de que,

A prescrição sociocognitiva supõe que a mente humana elabora e padroniza universos de experiência enquanto interage com o ambiente externo, e esta capacidade é o pré-requisito essencial para o desenvolvimento da inteligência e a aquisição de novos conhecimentos com base em outros já existentes (Gerhardt, 2006, p. 1186).

Contudo, a principal crítica assenta-se na adoção de modelos cognitivos individualistas para a construção de sistemas de recuperação da informação (Belkin, 1980; Ingwersen; 1992, 1996, 1999), partindo para uma dimensão teóricometodológica na adoção de um modelo qualitativo com abordagem coletivista, a qual envolva os processos cognitivos do sujeito associado ao contexto histórico, social e cultural mais amplo (Frohmann, 1990; Hjørland, 1997, 2002). Sob esta concepção, entende-se que a abordagem sociocognitiva atue como componente capaz de subsidiar investigações de tratamento e recuperação da informação documental considerando uma realidade mais representativa dos profissionais e usuários inseridos em contextos informacionais.

As necessidades informacionais do profissional durante o processamento e representação da informação são entendidas de fora para dentro, uma vez que o meio influencia e contribui para a construção dessa necessidade, refletindo no interesse real pela informação. Tais necessidades passam a serem representadas por meio dos modelos de mundo individuais, porém associados a uma concepção de mundo, ou seja, o modelo sociocognitivo atua como elemento imprescindível para a construção do próprio conhecimento e, paralelamente, da informação com valor social agregado, sendo este o principal ganho investigativo desta abordagem.
Sendo a catalogação de assunto um processo intelectual que visa compreender o valor informativo do texto com fins de representação documental, o contexto passa a ser considerado um elemento norteador das ações dos catalogadores de assunto, uma vez que estabelece e delimita as funções profissionais em ambientes institucionais. Com isso, o contexto atua como elemento intermediador entre a situação real do domínio em análise e os processos cognitivos que permeiam a atividade de leitura documental, norteada pelas concepções de análise de assunto utilizadas pelo profissional.

Fujita, Rubi e Boccato (2009) apontam que a abordagem sociocognitiva

[...] tem como foco o sujeito que realiza uma determinada atividade e sua cognição em relação ao seu contexto de produção.

Tal enunciado demonstra que o contexto sociocognitivo torna-se fundamental na catalogação de assunto, posto que o ato de tratar e representar de modo temático o estoque de conhecimentos acumulados constitui um dos mais importantes parâmetros do catalogador de assunto. Para tanto, o profissional antecede, cognitivamente, "[...] a trajetória lógica com a qual o usuário organiza seu pensamento para pesquisar a informação" e, paralelamente, buscar e apreender o conhecimento (Varela; Barbosa, 2007, p. 117). Sob este prisma, o processo de catalogação de assunto deve ser visto como uma etapa chave para a recuperação e transferência da informação. Verifica-se, então, que a catalogação de assunto e a recuperação da informação são faces de uma mesma moeda, ambas perpassadas pelas teorias cognitivas, fundamentais para o processo de construção e desconstrução do conhecimento, pois os conceitos atribuídos pelo catalogador de assunto (Lancaster, 2004, p. 06)

[...] servem como pontos de acesso mediante os quais um item é localizado e recuperado, durante uma busca por assunto [...]

Realizadas as contextualizações iniciais sobre a catalogação de assunto em perspectiva sociocognitiva, parte-se para uma análise das possíveis contribuições advindas desta abordagem investigativa como subsídio ao desenvolvimento de parâmetros metodológicos para a prática profissional.

\section{A prática profissional condicionada pela perspectiva sociocognitiva}

A análise de assunto está vinculada as ações particulares do catalogador de assunto enquanto leitor profissional e com a postura e objetivos 
do contexto de informação. Por sua vez, à influência profissional ocorre por meio de fatores inerentes ao funcionamento da mente humana, sendo estes (Naves, 2001, p. 191):

[...] subjetividade (diferentes indivíduos criam diferentes figuras ou idéias de uma mesma informação externa, por causa de suas inclinações pessoais e afetivas, que certamente interferem no trabalho por eles desenvolvido), o conhecimento prévio (se refere ao estoque de conhecimento armazenado na memória do indivíduo, assimilado e adquirido em suas vivências) e a formação e experiência (um mínimo de conhecimentos da área em que se está indexando.

Assim, os problemas existentes no processamento e representação da informação podem e devem ser investigados em uma abrangência maior pelo domínio do processo de conhecer, especialmente ao ser incorporado o enfoque multifacetado de novos conhecimentos às técnicas de tratamento informacional. Considerando que o conhecimento prévio/cognição profissional faz parte do contexto sociocognitivo enquanto uma representação mental do leitor, torna-se importante considerar a visão teórica de Hjørland (2002a) quanto à proposta de interação entre $o$ sujeito e o ambiente social/organizacional por dois aspectos: a catalogação de assunto é uma operação intelectual que depende da cognição e; o domínio do contexto faz-se necessário para que a identificação e seleção de conceitos abarquem as necessidades dos usuários e do contexto de enunciação.

No entanto, a análise de assunto carece de investigações na esfera da atuação profissional, pois a maior parte das pesquisas em torno deste temário tende a identificar os padrões de processamento dos catalogadores de assunto, objetivando-se auxiliar no aperfeiçoamento desses instrumentos (Dias e Naves, 2007). Nestas pesquisas, busca-se identificar as estratégias capazes de extrair de um documento o seu assunto, em outras palavras, focam o processo em si. Em seu estudo, Dias e Naves (2007) apresenta algumas linhas de investigações e ressalta a sequência cronológica estabelecida por Pinto Molina (1994), denominada de analítico-sintético-textual, a qual descreve o processo da análise de assunto nos seguintes estágios consecutivos: estágio da leitura e compreensão; estágio da inferência (interpretação) e; estágio da síntese. Outra vertente de estudo foca a perspectiva do usuário, assim sendo, visa colocar o usuário no centro das preocupações da área. Por outro lado, compreende-se muito pouco sobre as ações do leitor profissional e sua influência no resultado final do processo de tratamento temático da informação devido à carência de pesquisas que explorem o catalo- gador de assunto com base na abordagem sociocognitiva.

Concernente a esfera profissional, tem-se na literatura especializada as pesquisas de Chu e O'Brien (1993) e de Naves (2001), cujo objetivo foi identificar possíveis obstáculos enfrentados pelos profissionais. Outra linha de investigação centra-se no momento da leitura, cujos principais estudiosos são Farrow (1991); Fujita (1999) e Neves (2006) que buscam compreender os processos realizados pelo leitor durante a leitura documental em sua atividade profissional. No âmbito nacional, o contexto sociocognitivo é abordado nas pesquisas de Fujita (2004-2006a, 2007b); Rubi et al., (2007); Gonçalves (2008); Rubi (2008); Dal' Evedove e Fujita (2008) e Fujita, Rubi e Boccato (2009), as quais arrolam investigações centradas nos profissionais e usuários, com fins de verificação das preferências e opiniões, identificando as dificuldades e os procedimentos utilizados no momento do tratamento, representação e no uso de serviços de recuperação da informação. Entretanto, expõe-se que as pesquisas sobre este aspecto são muito subjetivas, pois lidam com características sociocognitivas atuantes em contextos específicos, verificando a percepção de valor da informação por profissionais e usuários. Ademais, entende-se que as dificuldades enfrentadas pelos catalogadores de assunto, especificamente no momento da representação documental, carecem de uma reflexão maior no que tange a vinculação profissional em contextos de informação especializados.

Ratificando a necessidade deste enfoque investigativo, o estudo abarca os aspectos sociocognitivos do profissional, na tentativa de mensurar o verdadeiro impacto de suas ações particulares cotidianas desempenhadas na catalogação de assunto. Tal ênfase respalda-se na necessidade de "[...] refletir sobre o fazer profissional e sobre o "eu" diante de um mundo uno, somatório da objetivação e da subjetivação" (Varela, 2008, p. 23) que permeia a catalogação de assunto em ambiente específico.

\section{Metodologia}

A pesquisa tem caráter exploratório sendo utilizada a técnica introspectiva de coleta de dados - Protocolo Verbal, especificamente na modalidade de Protocolo Verbal em Grupo aplicada com três catalogadores de assunto de distintas bibliotecas universitárias do estado de São Paulo. Por sua vez, a observação centrou-se nos aspectos sociocognitivos que norteiam a prática profissional em catalogação de assunto ancorada na realidade própria do ambiente de trabalho. 
O contexto sociocognitivo constitui a interação entre processos cognitivos, de modo que os conhecimentos de diversas origens do profissional sejam parcialmente compartilhados (Koch, 2002). A pertinência de tais indicações baseia-se na importância do contexto durante a leitura documental ao fixar os objetivos e delimitar o desempenho profissional, pois o contexto sociocognitivo inclui todos os tipos de conhecimentos armazenados na memória denominada de "actantes sociais" que são utilizados durante um intercâmbio verbal.

A preocupação em torno do contexto sociocognitivo reside na busca por identificar as preferências e analisar as opiniões dos profissionais e usuários no processamento e representação documental, bem como no uso de serviços de busca e recuperação da informação, pois a articulação com os diversos agentes do fluxo e ciclo da informação é outro cuidado para se evitar desperdícios e lacunas.

Esclarece-se que a introspecção é um método por meio do qual o sujeito presta uma atenção meticulosa as suas próprias sensações e as relata de forma objetiva. Tem-se, pois, a introspecção como uma reflexão consciente sobre os conhecimentos e experiências anteriores realizadas pelo próprio ser, considerando-se que o conhecimento é um elemento pessoal e, sendo assim, subjetivo e conceitual. Para que o sujeito o comunique, o mesmo deve ser expresso, descrito ou representado em uma forma física. Dentre as técnicas de introspecção destaca-se o pensar alto (o sujeito pensa em voz alta enquanto realiza uma determinada atividade protocolo verbal ou análise de protocolo).

Portanto, a modalidade de Protocolo Verbal em Grupo inclui dados gerados a partir das manifestações espontâneas dos sujeitos participantes em eventos de leitura realizada colaborativamente para observação da cognição e conhecimento processual socialmente construído. Para a aplicação da técnica utilizou-se o estudo de Dias e Naves (2007) intitulado "Análise de Assunto", o qual suscitou e condicionou a discussão dos sujeitos participantes em torno da subjetividade que permeia a prática do catalogador de assunto.

\section{Resultados e discussão}

A análise dos dados coletados foi observada a partir da leitura detalhada das falas dos sujeitos participantes, as quais seguem a indicação de cada catalogador de assunto com o propósito de evidenciar cada uma das partes envolvidas na discussão. Salienta-se que, dentre todas as verbalizações transcritas, expõem-se apenas aquelas que melhor explicitam o temário abordado, a saber: Unidade de análise 1 (turnos 1 a 8) - Subjetividade do processo.

O desafio que se apresenta aos profissionais no processamento da informação assenta-se em catalogar os documentos de modo a estabelecer sintonia entre os conceitos representativos e a demanda do usuário, considerando que tal demanda é singular e circunstancial, especificamente no que tange a atribuição de significados.

2. Catalogador B: É complicada essa história da subjetividade, porque inevitavelmente se hoje eu classifico um documento em determinado lugar amanhã isso pode ser alterado pela necessidade da comunidade que eu atendo, do avanço científico e da alteração ocorrida no decorrer da minha vida profissional, porque eu vou aprendendo coisas novas e isso certamente vai me influenciar no momento de classificar e catalogar um documento.

3. Catalogador C: A gente quando trata o documento sempre pensa em que lugar o documento seria mais utilizado, ou seja, quais assuntos meIhor caracterizam o documento pensando mesmo na demanda do usuário. Obviamente muitas vezes agente usa do bom senso.

4. Catalogador A: Eu percebo muito a importância do conhecimento do catalogador sobre a área em que está atuando, o famoso conhecimento prévio do profissional principalmente para a área de humanas, porque é uma área subjetiva por natureza, então seria muito mais rico se houvesse esse conhecimento, consequentemente o usuário e o catalogador estariam falando a mesma língua.

Os estudos devem abordar as ações cotidianas do catalogador de assunto e suas articulações nos diferentes contextos informacionais, a fim de observar a real situação dos produtos e serviços concomitantes ao bojo teórico-prático da catalogação de assunto, considerando-se que a atuação profissional e o contexto de trabalho constituem uma unidade inseparável, cuja dinâmica de interação tende a ser contínua.

5. Catalogador C: A teoria até pode direcionar, mas é complicado colocar na prática diária porque a realidade é diferente.

6. Catalogador A: Por mais que agente conheça a literatura, o dia a dia exige uma postura diferente, sei lá, um agir mais visando as necessidades da biblioteca e aí tudo começa a ser mais natural mesmo. [...] Mas, por mais que agente saiba que se deve seguir a literatura, se preocupar mesmo com a forma dita correta de se catalogar, pelo menos a minha prática não é tão certinha [...] conforme os apontamentos da literatura.

A percepção dos catalogadores de assunto pela perspectiva sociocognitiva reforça o fato da atuação profissional em catalogação de assunto não ser apenas um processo técnico, mas ba- 
sear-se em reflexões pessoais e coletivas mediante preparo intelectual, especificamente por meio do conhecimento prévio. Isto porque, a experiência profissional condiciona as ações cotidianas, as quais exigem comportamentos diferenciados dos preconizados pela literatura especializada, fator que reforça a necessidade de parâmetros específicos que retratem a realidade própria de cada contexto de informação.

Este aspecto baseia-se no entendimento de que, mediante a compreensão do contexto de atuação e todas as suas características inerentes, o catalogador de assunto seja capaz de refletir sociocognitivamente e não centrar a realização do processo por meio do bom senso profissional.

7. Catalogador B: O profissional na hora de atuar tem que pela intuição trazer a teoria para a sua realidade e muitas vezes você nem acaba seguindo a teoria, porque ela não corresponde a sua necessidade.

8. Catalogador C: Eu não realizo tudo o que é preconizado pela teoria, eu acaba indo de encontro com o meu conhecimento tácito.

Salienta-se, mediante os resultados ora expostos, que a catalogação de assunto não é apenas uma categorização simplista de assuntos. No entendimento de Varela e Barbosa (2007), constitui um "[...] processo intelectual de análise de conteúdo e representação simbólica deste conteúdo, no qual está implícita a ação de busca e recuperação da informação, praticada pelo usuário na fase seguinte". Logo, configura-se como uma operação complexa e de múltiplas vertentes, sendo formada por dois atores - catalogador de assunto e usuário -, "[...] cujas linhas de pensamento vão se encontrar em algum momento no tempo" (Varela; Barbosa, 2007, p. 124).

A catalogação de assunto assume uma dimensão estratégica na atual sociedade, visto que o documento é o representante, substituto ou mesmo 'espelho das ideias do homem'. Portanto, a investigação das ações dos catalogadores de assunto pela perspectiva sociocognitiva fazse necessária, na medida em que o exame desses aspectos viabiliza subsídios contributivos em torno das principais influências e características que circundam a prática profissional. Nesta esfera, o ser humano deve ser o objetivo principal dos avanços científicos em catalogação de assunto, visto que o profissional é conhecedor e observador da realidade na qual a informação é cuidadosamente tratada com fins de disseminação futura. Seguramente, toda construção do conhecimento deve respaldar-se no contexto social, em que "a historicidade dos sujeitos cognoscentes e dos objetos cognoscíveis [...]" de- vem ser consideradas, a fim de colocá-los em uma relação culturalmente determinada (Cardoso, 1996, p. 111).

Ainda há muito que se explorar em termos de prática profissional sob orientações cognitiva e social em catalogação de assunto. A primeira, insatisfatória, e a segunda, fortemente exaltada. No entanto, acredita-se que seja na esfera social e cognitiva que os estudos devam se desenvolver, pois para que a informação tenha utilidade máxima, primeiramente é preciso atribuir valor a seus facilitadores de difusão informacional na esfera social.

Talvez, o que falte a Ciência da Informação seja compreender o entremeio entre informação (objeto de estudo investigado sob orientação dos paradigmas dominantes) e usuário (finalidade maior do existir em si mesma enquanto campo científico). Para tanto, deve-se voltar os olhos para o profissional, elemento que na maioria das vezes é imperceptível aos que professam desvendar as lacunas e supostos domínios em Ciência da Informação. Ao se professar sobre a função social do catalogador de assunto, necessita-se não apenas defini-lo como agente de transformação social mediante todas as suas ricas possibilidades de atuação, mas, também, compreendê-lo enquanto elo cognoscente entre a informação e o usuário.

Avançar em observações que abordem a prática profissional em ambiente específico é fator emergente para compreender as mudanças estruturais de ordem social e cognitiva pelas quais os catalogadores de assunto e o contexto informacional passam constantemente. Para tanto, a abordagem sociocognitiva mostra-se relevante e um posicionamento enriquecedor para as pesquisas em catalogação de assunto que busquem o entendimento e exaltação da informação construída na esfera social.

Este olhar investigativo tende a respaldar os anseios profissionais por um instrumento que abarque a visão mais ampla do contexto e suas configurações em um cenário contemporâneo, dinâmico e mutante. Todavia, a prática profissional deve ser o centro das investigações de abordagem teórico-metodológica em catalogação de assunto, pois as ações cotidianas dos catalogadores de assunto possuem dispares comportamentais que influenciam na qualidade dos produtos e serviços informacionais e sua efetiva recuperação nos sistemas de informação.

\section{Considerações finais}

As reflexões expostas apontam que os esforços em catalogação de assunto devem ser direcio- 
nados para uma dimensão teórica focada em abordagens sociocognitivas centradas no contexto social da informação, do profissional e do usuário. Isto porque, as reflexões sobre o processo sociocognitivo no decurso das ações profissionais constituem uma rica fonte geradora de conhecimentos científicos que tendem a contribuir para a melhoria da qualidade da catalogação de assunto em nível prático.

Por mais subjetivas e particulares que sejam as ações profissionais durante a catalogação de assunto, muitas são decorrentes da falta de instrumentos e parâmetros direcionados para a realidade da prática profissional, esta altamente dependente do contexto informacional em que o catalogador de assunto está inserido. Sendo assim, tem-se a necessidade da literatura especializada direcionar sua atenção para o estabelecimento de parâmetros metodológicos baseados não apenas nos aportes teóricos, mas que atenda e cerque as características e singularidades específicas de cada contexto informacional, bem como de seus profissionais, ou seja, instrumentos que reflitam a prática cotidiana do processo.

Associado ao contexto sociocognitivo as visões holísticas e coletivísticas dos profissionais são elementos contribuintes para a sistematização da catalogação de assunto. A opinião profissional torna-se de grande valia para o estabelecimento e avaliação dos instrumentos que conduzirão a consecução da catalogação de assunto no contexto informacional. Nesta esfera, defende-se o desenvolvimento de formas investigativas centradas na prática da catalogação de assunto pela perspectiva sociocognitiva. Certamente, algo que demanda uma atenção especial ao catalogador de assunto e todas as suas manifestações perceptíveis no momento da realização da catalogação de assunto.

\section{Notas}

(1) Pode-se aludir que a missão seja "[...] a consciência que cada homem tem de seu mais autêntico ser, daquilo que está chamado a realizar. A idéia de missão é, pois, um ingrediente constitutivo da condição humana [...]" (Ortega y Gasset, 1929, p. 07).

(2) O fenômeno da percepção é um processo relativo ao percurso mental da informação ou como uma teoria de tratamento da informação (Fortin, Rousseau, 1998).

(3) Salienta-se que a padronização da representação, atrelada a cultura particular do profissional, substancialmente impõe uma visão reducionista de uma única cultura, a qual pode estar arraigada de preconceitos e tende a refletir valores próprios. Isto, por certo, priva a garantia literária e cultural da informação.

\section{Referencias}

Belkin, N. J. (1980). Anomalous State of Knowledge as basis for information retrieval. // The Canadian Journal of Information Science. ISSN 19119593. 5:1 (1980) 133-143.

Belkin, N. J.; Robertson, S. (1976). Information Science and the phenomenon of information. // Journal of the American Society for Information Science. ISSN 0002-8231. 37:4 (1976) 197-204.

Borko, H. (1968). Information science: what is it? // American Documentation. ISSN 0096-946X. 19:1 (1968) 3-5.

Cardoso, A. M. P. (1996). Pós-Modernidade e informação: conceitos complementares? // Perspectivas em Ciência da Informação ISSN 1981-5344. 1:1 (Jan./Jul. 1996) 6379.

Chu, C. M.; O'Brien, A. (1993). Subject analysis: the critical first stages in indexing. // Journal of Information Science. ISSN 0165-5515. 19: 6 (1993) 439-454.

Dal' Evedove, P. R.; Fujita, M. S. L. (2008). A Cognição profissional de catalogadores de assunto em contexto de biblioteca universitária. // Seminário Nacional de Bibliotecas Universitárias- SNBU, 15., 2008, São Paulo. Anais... São Paulo: CRUESP, 2008. p. 1-15. http://www.sbu.unicamp.br/snbu2008/anais/site/pdfs/319 8.pdf (2010-03- 26).

Dias, E. W.; Naves, M. M. L. (2007). Análise de Assunto: teoria e prática. Barsília: Thesaurus, 2007. ISBN 978857062620.

Fortin, C.; Rousseau, R. (1998). Psychologie Cognitive: une approche de traitement de l'information. Québec: Téléuniversité, 1998. ISBN 978-2762400878.

Gerhardt, A. F. L. M. (2006). Uma visão sociocognitiva da avaliação em textos escolares. // Educ. Soc. ISSN 01017330. 27:97 (Set./Dez. 2006) 1181-1203.

Goldmann, L. (1973). Lukacs et Heidegger. Paris: DenoelGonthier, 1973. ISBN 13: 9780710087942.

Gonçalves, M. C. (2008). A indexação em catálogos on-line de bibliotecas universitárias na percepção de usuários integrantes de grupos de pesquisa: uma contribuição ao desenvolvimento de política de indexação na rede de bibliotecas da UNESP. Marília: Universidade Estadual Paulista, Faculdade de Filosofia e Ciências, 2008. Dissertação de Mestrado. http://www.marilia.unesp.br/ Home/PosGraducao/Ciênciadalnformação/Dissertacoes/ goncalves_mc_me_mar.pdf. (2010-04-01).

Farrow, J. F. A. (1991). A cognitive process model of document indexing. // Journal of Documentation. ISSN 00220418. 47: 2 (1991) 149-166.

Frohmann, B. (1990). Rules of indexing: a critique of mentalism in information retrieval theory. // Journal of Documentation. ISSN 0022-0418. 46:2 (1990) 81-101.

Fujita, M. S. L. (1999). A leitura em análise documentária: relatório parcial. Marília: UNESP; CNPq, 1999. Projeto Integrado de Pesquisa.

Fujita, M. S. L. (2007). La enseñanza de la lectura documentaria en el abordaje cognitivo y sociocognitivo: orientaciones a la formación del indizador. // Anales de Documentación. ISSN 1575-243. 10 (2007) 397-412.

Fujita, M. S. L.; Rubi, M. P.; Boccato, V. R. C. (2009). O contexto sociocognitivo do catalogador em bibliotecas universitárias: perspectivas para uma política de tratamento da informação documentária. // DataGramaZero. ISSN 1517-3801. 10:2 (April 2009)

Hjørland, B. (2002). Domain analysis in information science: eleven approaches-traditional as well as innovative. // Journal of Documentation. ISSN 0022-0418. 58 (2002) 422-462. 
Hjørland, B. (1997). Information seeking and subject representation: an activity-theoretical approach to information science. Westport: Greenwood Press, 1997. ISBN 9780313298936.

Ingwersen, p. (1999). Cognitive information retrieval. // Annual Review of Information Science and Technology. ISSN 0066-4200. 34:1 (1999) 3-52.

Ingwersen, p. (1996). Cognitive perspectives of information retrieval interaction: elements of a Cognitive IR Theory. // Journal of Documentation. ISSN 0022-0418. 52:1 (1996) 3-50.

Ingwersen, p. (1992). Information retrieval interaction. London: Taylor Graham, 1992. ISBN 0947568549.

Koch, I. G. V. (2002). Desvendando os segredos do texto. São Paulo: Cortez, 2002. ISBN 8524908378.

Lancaster, F. W. (2004). Indexação e resumos: teoria e prática. Tradução de Antonio Agenor Briquet de Lemos. 2. ed. Brasília: Briquet de Lemos, 2004. ISBN 85$8563724=2$.

Naves, M. M. L. (2002). El trabajo de los indizadores: factores que afectan al análisis de contenido. // Scire. ISSN 1135-3716. 8:1 (En./Jun. 2002) 119-130.

Naves, M. N. L. (2001). Estudo dos fatores interferentes no processo de análise de assunto. // Perspectivas em Ciência da Informação. ISSN 1413-9936. 6:2 (Jul./Dez. 2001) 189-203.

Neves, D. A. B. (2006). Ciência da Informação e cognição humana: uma abordagem do processamento da informação. // Ciência da Informação. ISSN 0100-1965. 35:1 (Jan./Abr. 2006) 39-44.

Novellino, M. S. F. (1996). Instrumentos e metodologias de representação da informação. // Informação \& Informação. ISSN 1981-8920. 1:2 (Jul./Dez. 1996) 37-45.

Ortega y Gasset. (1929). La Rebelion de las Massas, Madrid: Revista de Occidente. 1929.

Pinto Molina, M. (1993). Análisis documental: fundamentos y procedimientos. 2. ed. rev. y aum. Madrid: EUDEMA, 1993. ISBN 84-7754-070-5.

Pinto Molina, M. (1994). Interdisciplinary approaches to the concept and practice of written text documentary content analysis (WTDCA). // Journal of Documentation. ISSN 0022-0418. 58. 50:2 (1994) 111-133.

Rubi, M. P. et al. (2007). Política del tratamiento de la información documentaria en bibliotecas universitarias: estudio diagnóstico del contexto en la perspectiva del catalogador y del usuario. // Scire. ISSN 1135-3716. (2007) 71-77.

Rubi, M. P. (2008). Política de indexação para construção de catálogos coletivos em bibliotecas universitárias. Marília: Faculdade de Filosofia e Ciências, Universidade Estadual Paulista, 2008. Tese de Doutorado. http://www.unesp.br/cgb/int_conteudo_sem_img.php?co nteudo=562 . (2010-03-07)

Salles, J. F.; Parente, M. A. M. P. (2002). Processos Cognitivos na Leitura de Palavras em Crianças: relações com Compreensão e Tempo de Leitura. // Psicologia: reflexão e crítica. ISSN 0102-7972. 15:2 (2002) 321-331.

Sauperl, A. (2002). Subject determination during the catalog process. Lanham: Scarecrow, 2002.

Shera, J. (1973). Toward a theory of librarianship and information science. // Ciência da Informação. ISSN 01001965. 2:2 (1973) 87-97.

Varela, A. V.; Barbosa, M. L. A. (2007). Aplicação de teorias cognitivas no tratamento da informação. // Revista Brasileira de Biblioteconomia e Documentação. ISSN 19806949. 3:2 (Jul./Dez. 2007) 116-128.

Varela, A. V. (2008). Informação, cognição e mediação: vertentes, contextos e pretextos. // Revista Ibero- americana de Ciência da Informação. 1:1 (Jan./Abr. 2008) 21-45.

Ward, M. (1996). The future of the human indexer. Journal of Librarianship and Information. // Science. ISSN 09610006. $28: 4$ (1996) 217-225.

Recibido: 2010-04-15. Revisado: 2010-06-29. Aceptado: 2010-07-07. 
